\title{
A Model for Standardizing Manipulation Terminology in Physical Therapy Practice
}

\author{
Paul E. Mintken, PT, DPT, OCS ${ }^{1}$; \\ Carl DeRosa, PT, PhD, DPT, FAPTA'; \\ Tamara Little, PT, DMT, FAAOMPT ${ }^{3}$; \\ Britt Smith, PT, DPT, OCS, FAAOMPT ${ }^{4}$ for the American Academy \\ of Orthopaedic Manual Physical Therapists.
}

\section{Preface}

Research supporting the efficacy of manual therapy, manipulation in particular, is growing. The ability to communicate clearly and accurately regarding this important intervention, regardless of region or background, is essential if clinicians are to incorporate this research in clinical practice. In February 2007, the American Academy of Orthopaedic Manual Physical Therapists formed a task force to standardize manual therapy terminology, starting with the intervention of manipulation. The ultimate goal of this task force was to create a template that has the potential to be used internationally by the community of physical therapists in order to standardize manual therapy nomenclature. The following

${ }^{1}$ Chair of the Task Force; Assistant Professor, University of Colorado Denver, School of Medicine, Physical Therapy Program, Denver, CO; Fellow, Regis University Manual Therapy Fellowship, Regis University, School of Physical Therapy, Denver, CO.

${ }^{2}$ Professor, Physical Therapy Program, Northern Arizona University, Flagstaff, AZ.

${ }^{3}$ Associate Professor, University of the Pacific School of Pharmacy and Health Sciences, Department of Physical Therapy, Stockton, CA.

${ }^{4}$ Physical therapist/owner private practice, SOAR Physical Therapy, Grand Junction, CO.

"Copyright held by the American Academy of Orthopaedic Manual Physical Therapists (AAOMPT). JMMT publishes these clinical guidelines with AAOMPT's permission."

Address correspondence to Dr Paul Mintken,

University of Colorado Denver, School of Medicine,

Physical Therapy Program, C244, Education 2 South,

Bldg L28, Room 3128, 13121 E 17th Avenue, PO Box 6508,

Aurora, Colorado 80045.

E-mail: paul.mintken@uchsc.edu document reflects the work and recommendations of this task force.

We propose describing a manipulative technique using 6 characteristics:

1. Rate of force application: Describe the rate at which the force was applied.

2. Location in range of available movement: Describe whether motion was intended to occur only at the beginning of the available range of movement, towards the middle of the available range of movement, or at the end point of the available range of movement.

3. Direction of force: Describe the direction in which the therapist imparts the force.

4. Target of force: Describe the location to which the therapist intended to apply the force.

5. Relative structural movement: Describe which structure or region was intended to remain stable and which structure or region was intended to move, with the moving structure or region being named first and the stable segment named second, separated by the word "on."

6. Patient position: Describe the position of the patient, for example, supine, prone, recumbent. This would include any premanipulative positioning of a region of the body, such as being positioned in rotation or side bending.

Manipulation is one of the oldest interventions in medicine and has a rich, diverse, and often turbulent history. References to manipulation in the healing arts date back over 4000 years, with discussions found in Egyptian scrolls (Edwin Smith papyrus) and enshrined in ancient Thai sculpture $^{1,2}$. Hippocrates described anatomy, spinal manipulation, and the reduction of dislocations and fractures with manipulative techniques, which were canonized in the writings of the Roman physician Galen ${ }^{3-5}$.

Manipulation has long been practiced by a wide variety of clinicians and lay practitioners in what may be termed sanctioned and nonsanctioned environments ${ }^{6}$. Physicians, 
physical therapists, chiropractors, and osteopathic physicians typically practice in sanctioned environments-ie, those legitimized through a formal (often legal) recognition process. Since the mid-19th century and early 20th century, western societies have sanctioned practice through a process of licensure, state practice acts, and regulation of the professional education process ${ }^{7}$.

Manipulation has also been utilized by a broad array of lay practitioners, ranging from masseurs and masseuses to bodyworkers, fitness, and self-proclaimed health specialists and healers ${ }^{6}$. These individuals primarily practice in nonsanctioned environments, with legitimacy established through cultural norms and practices but not through traditional societal or legal forms of recognition.

Health care professionals practicing in the sanctioned environments have long engaged in dialectic with nonsanctioned practitioners. Wharton Hood, a physician, studied manipulation under the guidance of Richard Hutton, a bonesetter8. James Paget, an early medical pioneer in orthopaedics, admonished his colleagues in a lecture on bonesetting by noting "few of you are likely to practice without having a bonesetter for a rival; and if he can cure a case which you have failed to cure, his fortune will be made and yours marred. ... Learn, then, to imitate what is good and avoid what is bad in the practice of bonesetters.". Robert Jones, the eminent British orthopaedic surgeon in the early 20th century, echoed Paget with the comment, "We should mend our ways rather than abuse the unqualified. Dramatic success in their hands should cause us to inquire as to the reason; it is not wise or dignified to waste time denouncing their mistakes for we cannot hide the fact that their success is our failure ${ }^{10}$." These skilled physicians were keen on examining the nonsanctioned practice of bonesetting to better inform and improve the sanctioned environment and care.

Although both sanctioned and nonsanctioned practitioners may use the same manipulative techniques, the environments in which they practice remain quite different ${ }^{6}$. Practitioners in nonsanctioned settings are typically not bound by the same legal and societal constraints as practitioners in sanctioned environments (eg, state practice acts). As a result, there has been little formal scientific investigation into the efficacy and the theoretical basis to support the credibility of the use of manipulative techniques in these environments. Conversely, as manipulative techniques have become integrated into the practice of a wide array of clinicians practicing in sanctioned settings, studies analyzing the efficacy of these techniques have proliferated ${ }^{11-17}$. Unfortunately, the clinicians and lay practitioners who historically have used, and now use, manipulations have continued to use a broad array of descriptive terminology, congruent with their wide variety of theoretical constructs and schemata.
This has rendered meaningful discussion of manipulative techniques nearly impossible.

Physical therapists in particular are not immune to the consequences of this history. John Mennell, MD stated that physical therapists used a confusing array of terms that "cloud the issue by talking about degrees of manipulation using such terms as articulation and mobilization leading up to manipulation ${ }^{6}$." Such a woeful lack of language specificity ultimately precludes any ability to compare and contrast the intervention or the outcome and minimizes any opportunity to ultimately discern effective from ineffective. Furthermore, despite Mennell's caution appearing many years ago, one could argue that the clarity of language with respect to manipulation has not improved, but in fact has worsened. Seminal documents from noted professional associations and organizations, such as the American Physical Therapy Association ${ }^{18-20}$, the American Academy of Orthopaedic Manual Physical Therapists ${ }^{19}$, and the International Federation of Orthopaedic Manipulative Therapists ${ }^{21}$, interchange such terms as manual therapy, mobilization, and manipulation with the implication often being that they are synonymous.

As the evidence supporting the beneficial effects of ma-

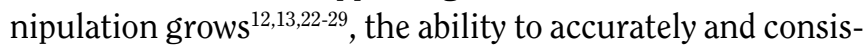
tently describe these interventions intraprofessionally and interprofessionally becomes essential. In a recent editorial, Oostendorp ${ }^{30}$ stated that one of the main obstacles to the clinical application of current research is the lack of specific descriptions of the interventions used, and called for the development of an internationally accepted nomenclature for describing manual physical therapy interventions. At a minimum, it is in the patient's best interest if an intervention is described in such a way that it may be precisely replicated by different physical therapists. It is only when interventions can be clearly understood and adequately described that they can be reliably replicated or applied, measured for effectiveness and efficiency, and disseminated and standardized through a uniform education process. Reliability requires that techniques be "operationalized" in plain, transparent language, so that a variety of practitioners can understand and practice the application in a like manner. Finally, the ability to transmit the practice from person to person and generation to generation will ultimately require a standardized, uniform language. The current state of affairs does not allow a meaningful discourse between students, academicians, and clinicians. Standardization of the descriptive language we use will provide an unambiguous platform on which the physical therapists of tomorrow may stand.

The aim of the task force created in February 2007 by the American Academy of Orthopaedic Manual Physical Therapists was to propose a model for standardized terminology to describe manipulative techniques as simply and 
clearly as possible in language that is understandable to all clinicians, regardless of individual clinical practices or schools of thought.

\section{Challenges of the Task}

In developing descriptive terminology for manipulative techniques that meets the above-stated aim, several important issues were considered by the task force.

First, it is tempting to digress from the task of describing a manipulative technique to larger theoretic, legal, political, and educational issues that often surround manipulation $^{31}$. For example, multiple theories exist to explain mechanisms of action and indications for techniques ${ }^{32-36}$. Issues also surround the efficacy of techniques ${ }^{37,38}$, qualifications for performing manipulations ${ }^{39}$, and the lack of consistent definitions regarding manual therapy and manipulation in general ${ }^{6,18-20}$. These issues are very important, and debate on these topics should and will continue. However, the task at hand was to create consistent terminology for the purpose of describing manipulative techniques that are interventions used in physical therapy practice. Further, terminology will not resolve differences between treatments, models, or clinical reasoning; it will simply aid in the fruitful discussion of such. Language cannot question or judge what physical therapists do or why they do it, but consistent terminology is necessary to discuss these issues.

Second, a successful model for describing techniques must avoid theoretical assumptions about mechanisms or intentions so as to remain useful and timeless as theory evolves. This includes the avoidance of theory that is considered the best evidence of the day. It is impossible on the front end to determine which theory will stand the test of time. Our profession is rife with examples of descriptive terminology that imply outdated theory, and it will not serve the profession well to repeat this process.

Third, terminology must be easily understood by clinicians from multiple backgrounds and should not reflect a particular history. The current language used to describe manipulative techniques within the profession of physical therapy includes a dizzying array of terminology that reflects the multiple ways in which therapists have obtained training in these techniques ${ }^{40-43}$. Training in manipulative techniques until recently was obtained almost solely through postprofessional education. Postprofessional educational programs have little incentive to develop language consistent with that of other postprofessional programs; in fact, there is some incentive to retain language that reflects the unique culture of the individual program. Because particular terms are associated with individual schools, programs, or regions, assumptions about the theory behind the application are often connected to the terminology itself. This can result in a con- versation about a technique being confused with a conversation about the reason one might apply the technique, the theory behind the technique, and what one might expect the technique to accomplish.

\section{Describing a Manipulative Technique}

Several issues must be clarified in order to lay the groundwork for a descriptive framework. First, while spinal manipulation consistently receives the greatest attention in any such discussion, manipulative techniques are by no means limited to the spine. It would be a mistake to develop a descriptive framework that is limited to spinal manipulation, as ignoring the peripheral regions would ultimately set the stage for 2 separate frameworks to describe manipulative techniques.

Second, the terms manipulation and mobilization are frequently interchanged or used as if they are one and the same $e^{6,18-20,42}$. For the purpose of developing a conceptual framework, the task force chose to describe a manipulation as a definable intervention within the scope of physical therapy practice with a given set of characteristics. In our opinion and for our purpose, the difference between manipulation and mobilization or between manipulation and another comparable physical therapy intervention rests in how the individual characteristics are modified. For the purposes of this descriptive framework, we have limited the discussion to manipulation techniques. The task force is in support of the definition in the Guide to Physical Therapist Practice ${ }^{18}$ and, therefore, suggests that the same framework outlined below may be used to describe any intervention that has the same set of characteristics, and this would include many interventions that are now commonly termed mobilizations.

Third, the ability to apply a manipulation to a highly localized, discreet region remains a matter of debate $e^{44-52}$. A framework for describing the technique is necessarily limited to describing where and how the force was directed. What happens as a result of that force is a matter to be investigated, and a consistent terminology should aid in that investigation.

Fourth, the language of biomechanics ${ }^{53,54}$ and anatomy $y^{55}$ already provides terminology that is universally understood internally and externally, and potentially quite precise for the purposes of describing the location and type of forces applied to the human body. For this reason the task force attempted to use descriptive terminology from these 2 scientific vantage points a priori whenever possible. Some of this language has been used to describe a variety of theoretical models associated with particular schools of thought in the past. The mere use of the same widely used and understood language should not be confused with the adoption of any particular school of thought. 


\section{Proposed Framework for Describing Any Manipulation Intervention.}

We propose describing a manipulative technique using 6 characteristics:

1. Rate of force application: Describe the rate at which the force was applied.

2. Location in range of available movement: Describe whether motion was intended to occur only at the beginning, towards the middle, or at the end point of the available range of movement. The term available range of movement is intended to describe the available movement as perceived by the therapist after the patient has been positioned and at the time the technique is applied. The available movement may or may not be the same as the range of motion available at a particular joint or region under other circumstances. The use of the terms beginning, mid, and end point of available movement are only relevant in the context of describing the particular technique at the time it is applied. The term end point should not be associated with any particular anatomic structures, as many structures have the potential to limit motion depending on the individual patient and technique.

3. Direction of force: Describe the direction in which the therapist imparts the force. This description should be devoid of the "intent" of the technique and, instead, should follow standard anatomical and biomechanical conventions.

4. Target of force: Describe the location where the therapist intended to apply the force. In the case of the spine, force may be directed at a specific level, or more generally across a particular region such as mid lumbar or lower thoracic. The task force suggests that replication of techniques among therapists will be more easily achieved if clearly palpable structures are used as reference points. For most peripheral joints associated with the appendicular skeleton, the target of force may be appropriately described using a specific joint as a reference. It is important to note that the use of a joint, or a particular spinal level, for reference as to where the force is applied is not intended to imply any particular theoretical assumption as to structures affected by a manipulation, but only to provide information about where the force was applied.

5. Relative structural movement: Describe which structure or region was intended to remain stable and which structure or region was intended to move, naming the moving structure or region first and the stable segment second, separated by the word "on." For example, a "lower lumbar on upper lumbar" technique implies that the clinician intended to move the lower lumbar region while stabilizing the upper lumbar region. Techniques associated with the peripheral joints would be described utilizing the same convention (eg, tibia on femur, humerus on scapular glenoid).

6. Patient position: Describe the position of the patient (eg, supine, prone, recumbent). This would include any premanipulative positioning of a region of the body, such as being positioned in rotation or side bending.

Examples of using these 6 characteristics to describe a spinal manipulation technique are as follows:

A lumbar technique might be described as "A highvelocity, end-range, right-rotational force to the lower lumbar spine on the upper lumbar spine in a right side-lying, left lower thoracic lumbar side-bent position."

A thoracic technique might be described as "A highvelocity, mid-range, posterior-to-anterior force to the midthoracic spine on the upper thoracic spine in a prone position."

A cervical technique might be described as "A highvelocity end-range right lateral translational force to the lower cervical spine on the upper thoracic spine in supine, with slight cervical flexion."

\section{Concluding Thoughts and Future Recommendations}

The timeliness of-indeed, urgency for-wrapping a meaningful description around the intervention of manipulation stems from the current evidence supporting its use as a treatment option for several spinal conditions ${ }^{22,23,27,29,45}$. Our dilemma as a profession arises from the fact that there is scientifically sound evidence that a favorable outcome can be achieved using manipulation; however, this intervention cannot be described without using archaic, sometimes meaningless, jargon and, perhaps more importantly, terminology that implies scientifically flawed assumptions $^{56-60}$. The basis of this conundrum is perpetuated at all levels in our profession, from entry level to postprofessional, by textbooks and literature sources that continue to quote outdated, poorly validated, and sometimes blatantly inaccurate theory, despite current evidence disproving them ${ }^{48,56,58,59,61-71}$.

Continued usage of language that cannot be separated from old assumptions ultimately stifles meaningful dialogue about the potential mechanisms behind favorable outcomes associated with manipulations. Biomechanical and anatomic models have yet to fully explain why manipulation is beneficial, at least for certain subgroups of patients with musculoskeletal conditions ${ }^{22,23,27,29}$. Indeed, clinical tools commonly used to assess outcomes, such as the Oswestry, Roland Morris, Neck Disability Index, and Fear Avoidance Beliefs Ques- 
tionnaire, are largely measures of changes in the patient's perception of pain and disability as opposed to measures of structural or anatomical changes ${ }^{72-78}$. Waddell has demonstrated the low level of correlation between physical impairments (eg, range of motion) and the patients' pain and disability ${ }^{2,79}$. Using language that is not theoretically neutral weds us to theories of the past and implies a level of scientific certainty that does not exist.

It is an important time in our professional history. Further progress in establishing physical therapy as the first choice for nonsurgical management of musculoskeletal conditions, including spinal conditions, can only occur if we can introspectively study our interventions using a language that does not presume a particular theory, is commonly understood intraprofessionally, and is meaningful to other pro- fessions and the public. Thus it is timely to correct this current course. Clear, concise language expands our profession's opportunity to meaningfully communicate with the larger community of medical professionals as we seek to establish collegial relationships. Most importantly we extend our opportunities to communicate amongst ourselves in a manner that fosters our own professional growth. Using language that is accepted and universally understood will only advance our profession, and ultimately simplify the processes of teaching, learning, and researching manual physical therapy interventions.

We thank the American Academy of Orthopaedic Manual Physical Therapists for entrusting us with this project. We hope that our work stimulates further dialogue on this important topic.

\section{REFERENCES}

1. Cyriax JH. Text Book of Orthopaedic Medicine. Volume 1. 8th ed. London, UK: Bailliere Tindall; 1982.

2. Waddell G. The Back Pain Revolution. New York, NY: Churchill Livingstone; 1999.

3. Ackerknecht E. A Short History of Medicine. Baltimore, MD: Johns Hopkins University Press; 1982.

4. Porter R. The Greatest Benefit to Mankind: A Medical History of Humanity. New York, NY: W.W. Norton \& Co; 1997.

5. Withington E. Hippocrates. Volume 3. Cambridge, MA: Harvard University Press; 1968.

6. Paris SV. A history of manipulative therapy through the ages and up to the current controversy in the United States. J Man Manip Ther 2000;8:66-77.

7. Flexner A. Medical Education in the United States and Canada Bulletin Number Four (The Flexner Report). New York, NY: The Carnegie Foundation for the Advancement of Teaching; 1910.

8. Hood WP. On Bone Setting (So-Called) and Its Relation to the Treatment of Joints Crippled by Injury, Rheumatism, Inflammation, etc. London, UK: MacMillan \& Co; 1871.

9. Paget J. Cases that bone-setters cure. BMJ 1867;1:1-4.

10. Paris SV. The Spine: Etiology and Treatment of Dysfunction Including Joint Manipulation [course notes]; 1984.

11. Assendelft WJ, Koes BW, van der Heijden GJ, Bouter LM. The efficacy of chiropractic manipulation for back pain: blinded review of relevant randomized clinical trials. J Manipulative Physiol Ther 1992;15:487-494.

12. Bronfort G, Assendelft WJ, Evans R, Haas M, Bouter L. Efficacy of spinal manipulation for chronic headache: a systematic review. $J$ Manipulative Physiol Ther 2001;24:457-466.

13. Bronfort G, Haas M, Evans RL, Bouter LM. Efficacy of spinal manipulation and mobilization for low back pain and neck pain: a systematic review and best evidence synthesis. Spine J 2004;4:335-356.

14. Leaver AM, Refshauge KM, Maher CG, et al. Efficacy of manipulation for non-specific neck pain of recent onset: design of a randomised controlled trial. BMC Musculoskelet Disord 2007;8:18.
15. Leerberg E. Efficacy of spinal manipulation for low back pain has not been reliably shown. BMJ 1999;318:261-262.

16. Nelson CF, Bronfort G, Evans R, Boline P, Goldsmith C, Anderson AV. The efficacy of spinal manipulation, amitriptyline and the combination of both therapies for the prophylaxis of migraine headache. $J$ Manipulative Physiol Ther 1998;21:511-519.

17. Nwuga VC. Relative therapeutic efficacy of vertebral manipulation and conventional treatment in back pain management. Am J Phys Med 1982;61:273-278.

18. American Physical Therapy Association. Guide to Physical Therapist Practice. Second Edition. American Physical Therapy Association. Phys Ther 2001;81:9-746.

19. American Physical Therapy Association Manipulation Task Force MEC. Manipulation Education Manual for Physical Therapists Professional Degree Programs. Alexandria, VA: American Physical Therapy Association; 2004.

20. American Physical Therapy Association. Normative Model of Physical Therapist Professional Education: Version 2004. Alexandria, VA: American Physical Therapy Association; 2004.

21. International Federation of Orthopaedic Manipulative Therapists. Standards Document. Available at: http://www.ifomt.org/ifomt/about/ standards. Accessed September 4, 2007.

22. Childs JD, Fritz JM, Flynn TW, et al. A clinical prediction rule to identify patients with low back pain most likely to benefit from spinal manipulation: a validation study. Ann Intern Med 2004;141:920-928.

23. Cleland JA, Childs JD, Fritz JM, Whitman JM, Eberhart SL. Development of a clinical prediction rule for guiding treatment of a subgroup of patients with neck pain: use of thoracic spine manipulation, exercise, and patient education. Phys Ther 2007;87:9-23.

24. Cleland JA, Childs JD, McRae M, Palmer JA, Stowell T. Immediate effects of thoracic manipulation in patients with neck pain: a randomized clinical trial. Man Ther 2005;10:127-135.

25. Cleland JA, Fritz JM, Whitman JM, Childs JD, Palmer JA. The use of a lumbar spine manipulation technique by physical therapists in patients who satisfy a clinical prediction rule: a case series. J Orthop Sports Phys Ther 2006;36:209-214.

26. Cleland JA, Glynn P, Whitman JM, Eberhart SL, MacDonald C, Childs JD. Short-term effects of thrust versus nonthrust mobilization/ma- 
nipulation directed at the thoracic spine in patients with neck pain: a randomized clinical trial. Phys Ther 2007;87:431-440.

27. Flynn T, Fritz J, Whitman J, et al. A clinical prediction rule for classifying patients with low back pain who demonstrate short-term improvement with spinal manipulation. Spine 2002;27:2835-2843.

28. Fritz JM, Childs JD, Flynn TW. Pragmatic application of a clinical prediction rule in primary care to identify patients with low back pain with a good prognosis following a brief spinal manipulation intervention. BMC Fam Pract 2005;6:29.

29. Jull G, Trott P, Potter H, et al. A randomized controlled trial of exercise and manipulative therapy for cervicogenic headache. Spine 2002;27:1835-1843; discussion 1843.

30. Oostendorp RAB. Manual Physical Therapy in the Netherlands: reflecting on the past and planning for the future in an international perspective. J Man Manip Ther 2007;15:133-141.

31. Huijbregts PA. Chiropractic legal challenges to the physical therapy scope of practice: anybody else taking the ethical high ground? J Man Manip Ther 2007;15:69-80.

32. Maigne JY, Vautravers P. Mechanism of action of spinal manipulative therapy. Joint Bone Spine 2003;70:336-341.

33. Ross JK. Spinal manipulative therapy techniques: evaluating the mechanistic assumptions [thesis]. West Waterloo, Ontario, Canada: University of Waterloo; 2003.

34. Vernon H. Qualitative review of studies of manipulation-induced hypoalgesia. J Manipulative Physiol Ther 2000;23:134-138.

35. Vicenzino B, Collins D, Benson H, Wright A. An investigation of the interrelationship between manipulative therapy-induced hypoalgesia and sympathoexcitation. J Manipulative Physiol Ther 1998;21:448-453.

36. Wright A. Hypoalgesia post-manipulative therapy: a review of a potential neurophysiological mechanism. Man Ther 1995;1:11-16.

37. Assendelft WJ, Morton SC, Yu EI, Suttorp MJ, Shekelle PG. Spinal manipulative therapy for low back pain. Cochrane Database Syst Rev 2004;CD000447.

38. Ernst E, Canter PH. A systematic review of systematic reviews of spinal manipulation. $J$ R Soc Med 2006;99:192-196.

39. Whitman JM, Fritz JM, Childs JD. The influence of experience and specialty certifications on clinical outcomes for patients with low back pain treated within a standardized physical therapy management program. J Orthop Sports Phys Ther 2004;34:662-672; discussion $672-665$.

40. Wainner RS, Flynn TW, Whitman JW. Spinal and Extremity Manipulation: The Basic Skill Set for Physical Therapists [CD-ROM software]. San Antonio, TX: Manipulations Inc; 2001.

41. Greenman P. Principles of Manual Medicine. 2nd ed. Baltimore, MD: Williams \& Wilkins; 1996.

42. Maitland G, Hengeveld E, Banks K, English K. Maitland's Vertebral Manipulation. Oxford, UK: Butterworth-Heinemann; 2000.

43. McKenzie R. The Lumbar Spine: Mechanical Diagnosis and Therapy. Waikanae, New Zealand: Spinal Publications; 2003.

44. Beffa R, Mathews R. Does the adjustment cavitate the targeted joint? An investigation into the location of cavitation sounds. J Manipulative Physiol Ther 2004;27:e2.

45. Beneck GJ, Kulig K, Landel RF, Powers CM. The relationship between lumbar segmental motion and pain response produced by a posteriorto-anterior force in persons with nonspecific low back pain. J Orthop Sports Phys Ther 2005;35:203-209.

46. Chiradejnant A, Latimer J, Maher CG, Stepkovitch N. Does the choice of spinal level treated during posteroanterior (PA) mobilisation affect treatment outcome? Physiother Theor Pract 2002;18:

47. Chiradejnant A MC, Latimer J, Stepkovitch N. Efficacy of "therapistselected" versus "randomly selected" mobilisation techniques for the treatment of low back pain: a randomised controlled trial. Aust J Physiother 2003;49:233-241.

48. Haas M, Groupp E, Panzer D, Partna L, Lumsden S, Aickin M. Efficacy of cervical endplay assessment as an indicator for spinal manipulation. Spine 2003;28:1091-1096; discussion 1096.

49. Kulig K, Landel R, Powers CM. Assessment of lumbar spine kinematics using dynamic MRI: a proposed mechanism of sagittal plane motion induced by manual posterior-to-anterior mobilization. J Orthop Sports Phys Ther 2004;34:57-64.

50. Lee R, Evans J. An in vivo study of the intervertebral movements produced by posteroanterior mobilization. Clin Biomech (Bristol, Avon) 1997;12:400-408.

51. Lee RY, Tsung BY, Tong P, Evans J. Bending stiffness of the lumbar spine subjected to posteroanterior manipulative force. J Rehabil Res Dev 2005;42:167-174.

52. Ross JK, Bereznick DE, McGill SM. Determining cavitation location during lumbar and thoracic spinal manipulation: is spinal manipulation accurate and specific? Spine 2004;29:1452-1457.

53. Panjabi MM, White AA, 3rd, Brand RA, Jr. A note on defining body parts configurations. J Biomech. 1974;7:385-387.

54. White A, Panjabi M. Clinical Biomechanics of the Spine. 2nd ed. New York, NY: Lippincott Raven; 1990.

55. Federative Committee on Anatomical Terminology. Terminologia Anatomica. New York, NY: Thieme; 1998.

56. Cook C. Coupling behavior of the lumbar spine: a literature review. J Man Manip Ther 2003;11:137-145.

57. Cook C, Stickley L, Akram N, Benavides Y, Renz C, Ramey K. Interrater reliability of coupling pattern observations of the pathological lumbar spine: a pilot study. J Man Manip Ther 2004;12:192-198.

58. Legaspi 0, Edmond SL. Does the evidence support the existence of lumbar spine coupled motion? A critical review of the literature. $J$ Orthop Sports Phys Ther 2007;37:169-178.

59. Sizer PS, Jr., Brismee JM, Cook C. Coupling behavior of the thoracic spine: a systematic review of the literature. J Manipulative Physiol Ther 2007;30:390-399.

60. Sturesson B, Uden A, Vleeming A. A radiostereometric analysis of movements of the sacroiliac joints during the standing hip flexion test. Spine 2000;25:364-368.

61. Billis EV, Foster NE, Wright CC. Reproducibility and repeatability: errors of three groups of physiotherapists in locating spinal levels by palpation. Man Ther 2003;8:223-232.

62. Boline PD, Haas M, Meyer JJ, Kassak K, Nelson C, Keating JC, Jr. Interexaminer reliability of eight evaluative dimensions of lumbar segmental abnormality: Part II. J Manipulative Physiol Ther 1993;16:363-374.

63. Brandt C, Sole G, Krause MW, Nel M. An evidence-based review on the validity of the Kaltenborn rule as applied to the glenohumeral joint. Man Ther 2007;12:3-11.

64. Degenhardt BF, Snider KT, Snider EJ, Johnson JC. Interobserver reliability of osteopathic palpatory diagnostic tests of the lumbar spine: improvements from consensus training. J Am Osteopath Assoc 2005;105:465-473.

65. Downey BJ, Taylor NF, Niere KR. Manipulative physiotherapists can reliably palpate nominated lumbar spinal levels. Man Ther 1999;4:151-156.

66. Fritz JM, Whitman JM, Childs JD. Lumbar spine segmental mobility assessment: an examination of validity for determining intervention strategies in patients with low back pain. Arch Phys Med Rehabil 2005;86:1745-1752.

67. Hicks GE, Fritz JM, Delitto A, Mishock J. Interrater reliability of clinical examination measures for identification of lumbar segmental instability. Arch Phys Med Rehabil 2003;84:1858-1864. 
68. Huijbregts PA. Spinal motion palpation: a review of reliability studies. J Man Manip Ther 2002;10:24-39.

69. Maher CG, Latimer J, Adams R. An investigation of the reliability and validity of posteroanterior spinal stiffness judgments made using a reference-based protocol. Phys Ther 1998;78:829-837.

70. McKenzie AM, Taylor NF. Can physiotherapists locate lumbar spinal levels by palpation? Physiotherapy 1997;83:235-239.

71. Sebastian D, Chovvath R. Reliability of palpation assessment in nonneutral dysfunctions of the lumbar spine. Orthop Phys Ther Pract 2004; 16:23-26.

72. Cleland JA, Fritz JM, Whitman JM, Palmer JA. The reliability and construct validity of the Neck Disability Index and patient specific functional scale in patients with cervical radiculopathy. Spine 2006;31:598-602.

73. Davidson M, Keating JL. A comparison of five low back disability questionnaires: reliability and responsiveness. Phys Ther 2002;82:8-24.
74. Deyo RA, Battie M, Beurskens AJ, et al. Outcome measures for low back pain research. A proposal for standardized use. [Erratum appears in Spine. 1999;15:418]. Spine 1998;23:2003-2013.

75. Fairbank JC. The use of revised Oswestry Disability Questionnaire. Spine 2000;25:2846-2847.

76. Fairbank JC, Couper J, Davies JB, O'Brien JP. The Oswestry low back pain disability questionnaire. Physiotherapy 1980;66:271-273.

77. Fairbank JC, Pynsent PB. The Oswestry Disability Index. Spine 2000;25:2940-2952; discussion 2952.

78. Waddell G, Newton M, Henderson I, Somerville D, Main CJ. A Fear-Avoidance Beliefs Questionnaire (FABQ) and the role of fearavoidance beliefs in chronic low back pain and disability. Pain 1993;52:157-168.

79. Waddell G, Somerville D, Henderson I, Newton M. Objective clinical evaluation of physical impairment in chronic low back pain. Spine 1992;17:617-628.

\section{MANUAL THERAPY ANNOUNCEMENTS}

April 11-14, 2008. Portland, Oregon, USA.

North American Institute of Orthpaedic Manual Therapy (NAIOMT) "Spinal Manipulation: Thrusting Physical Therapy Forward"

Contact information: http://www.naiomt.com/ 2008Symp/courses.html

\section{April 18-20, 2008, Dunedin, New Zealand}

NZSP Conference

Contact information: https://apa.advsol.com.au

\section{May 23-24, 2008, Perth, Australia}

2008 APA National Congress: "Achieving the Vision"

Contact information: https://apa.advsol.com.au

\section{May 29-June 1, 2008, Ottawa, Canada}

Canadian Physiotherapy Association Congress 2008

Contact information: http://www.physiotherapy.ca

June 11-14, San Antonio, Texas; USA.

APTA Annual Conference. Contact information:

http://www.apta.org/
June 8-13, 2008, Rotterdam, the Netherlands

IFOMT Congress: "Connecting Science to

Quality of Life"

Contact information: http://www.ifomt2008.nl/

August 17-22, 2008, Glasgow, Scotland

$12^{\text {th }}$ World Congress on Pain

Contact information: http://www.iasp-pain.org/

September 26-28, 2008, Montreal, Canada

CPA Orthopaedic Division $19^{\text {th }}$ Orthopaedic

Symposium

Contact information:

http://symposiumortho2008.org/

October 30-November 2, 2008, Seattle, WA

2008 AAOMPT Conference: "Pain: From Science to Solution"

Contact information: http://aaompt.org/index.cfm

June 10-13, 2009. Baltimore, MD; USA.

APTA Annual Conference. Contact information: http://www.apta.org/ 